\title{
El caso de Alex Lora y El Tri: tensiones y altibajos en la estética urbana y la comunicación musical
}

The CASE of Alex Lora AND El Tri: THE TENSIONS AND THE UPS AND DOWNS IN URBAN AESTHETICS AND MUSICAL COMMUNICATION

\section{Tanius Karam}

Profesor Investigador de la Universidad Autónoma de la Ciudad de México. Investigador Nacional. Colaborador en revistas y otros medios especializados en comunicación.

E-mail: tanius@hotmail.com

Recibido el 29 de marzo de 2016. Aprobado el 30 de mayo de 2016.

\section{Resumen}

En este texto exponemos las contribuciones al rock mexicano del cantautor Alex Lora, vocalista y creador del grupo El Tri. Para contextualizar el trabajo hacemos un breve resumen de algunos momentos dentro del rock mexicano, sobre todo en la década de los ochenta, para luego comentar algunos aspectos dentro de la extensísima discografía de Lora de la que definimos su contribución dentro del rock urbano. En la segunda parte destacamos dos aspectos de la estética urbana de Lora: la construcción de uno de los principales sujetos discursivos en sus letras, la niñez y adolescencia del submundo urbano, y la construcción de un tipo de ciudad con las paradojas y contradicciones que nos parece representar. Definimos que la relación de Lora con el rock, sin negar su gran capacidad comunicativa, es una "tensa sintonía" entre aquello que reivindicaba en su producción de los setenta o parte de los ochenta, y la funcionalidad y adaptación de su imagen pública dentro de los grandes medios masivos, lo que parece en parte contradecir algunas de sus composiciones.

Palabras clave: Lenguaje. Sujeto discursivo. Espacio urbano. Medios y ciudades. Rock mexicano. Rock urbano. 


\section{Abstract}

In this paper we present the contributions of Alex Lora, lead singer and creator of the group "El Tri", to Mexican rock. To contextualize the work, we make a brief summary of some moments in Mexican rock, especially in the eighties, then discuss some aspects within Lora's very extensive discography, from which we define his contribution to urban rock. In the second part, we highlight two aspects of his urban aesthetics: the construction of one of the major discursive subjects in his lyrics, children and adolescents of the urban underworld, and the construction of a type of city with the paradoxes and contradictions that seem to represent us. We define the relationship between Lora and rock, without denying his great communication skills, as a "tight line" between what he claimed in his production in the seventies, or part of the eighties, and the functionality and adaptation of his public image within mass media, which seems to partly contradict some of his compositions.

Keywords: Language. Subject discourse. Urban space. Media and cities. Mexican rock. Urban rock.

\section{Presentación, algo de contexto de Lora}

En este trabajo queremos indagar la obra y discografía del rockero mexicano Alex Lora y ver una serie de movimientos en su construcción como personaje social, su estética, así como su relación con algunos de los objetos que abordó en sus letras, de manera particular la forma como trasluce algunos aspectos de la Ciudad de México.

A su manera Lora deviene en un cronista involuntario en el paso que ha supuesto la migración de las primeras etapas del rock, la anatemización del rock durante los setenta y su confección como expresión subterránea (underground) para luego posicionarse en el centro del escenario no solo con un público que más o menos le ha seguido por décadas, sino con una habilidad comunicativa para generar una presencia eficaz.

Para quienes no les gusta Lora, como aparecen algunos testimonios en el documental Resistencia. Retrato de Alejandro Lora (PADILLA, 2008) se trata de un cantante "majadero", dirigido a un cierto público que, por lo general, es el mismo, y siempre de hecho habla de lo mismo; puede tampoco gustar el que trata al destinatario como joven o chavo de una forma despectiva. Pero para sus seguidores, Lora es el mismo pulso del rock, es la posibilidad de llevar este género a todos los rincones y a todas las expresiones de la cultura popular. Aparte de estas tensiones en quien no se le puede regatear mérito por ser un emblema del rocanrol en México, prevalece el caso de su voz y estilo pegajoso y movido, dentro de lo que queremos ver principalmente un caso de éxito comunicativo y en la habilidad de este cantautor para conectar, muy a su manera, el submundo marginal 
de la zona metropolitana de la Ciudad de México con otros gustos, públicos y audiencias, incluso fuera de México.

Alejandro Lora Serna, mejor conocido como Alex Lora, nació en Puebla de Zaragoza el 1952, y se le reconoce generalmente como guitarrista y cantante de rock. Si bien en casi cincuenta años de vida artística el cantautor ha transitado por distintos horizontes en el mundo discográfico, mediático y cultural-urbano, su presencia es una de las más emblemáticas en este género por su constancia y visibilidad, originalmente en espacios muy acotados dentro del rol marginal pero lentamente logrando una proyección y visibilidad en espacios muy diversos donde se presentan Lora y su grupo.

Todo en Lora parece apuntar hacia un símbolo en la historia reciente mexicana. El debut de Three souls in my mind (1968) se hizo la emblemática fecha del 12 de octubre de 1968 (NOCHES CON PLATANITO, 2013), inicio de las Olimpiadas en México que iban a suspenderse tras haberse dado la matanza del 2 de octubre de 1968 en la zona de la ciudad conocida como Tlatelolco en la que miles de estudiantes desaparecieron y muchos más murieron tras las irrupción violenta de la policía y fuerzas militares a la plaza de Tlatelolco. Tres años después, en 1971, se dio el célebre festival de Avándaro, especie Woodstock mexicano que emula en su significado e impacto el festival estadunidense, y constituye quizá la principal efeméride de la historia del rock en el país.

Al inicio Three souls in my mind cantaba solo en inglés, pero ya en los setenta, los de la banda decidieron ya componer en español ya que consideraban un principio comunicativo: era importante que la gente entendiera el mensaje de sus canciones. En 1983 el grupo se disolvió, una batalla legal impidió que Lora se quedara con el nombre del grupo, y entonces fundó El Tri en el que juega con la fonética como era conocido el grupo con el título en inglés. El Tri no solo va a ser una clara huella de reconocimiento, sino que va a imprimir algo que nos interesa subrayar en la comunicación de Lora, la mexicanización del rock, de sus letras y de su performance como cantautor ${ }^{1}$.

Otro de los rasgos musicales de Lora es su abundancia: más de cuatrocientas canciones distribuidas en treinta discos, algunos de sus cuyos temas son muy gráficos e indican algo de su contenido como "Triste canción", "El fantasma del metro", "Niño sin amor", "Los minusválidos", "El indocumentado"; otras remiten a situaciones o aspectos de la vida nacional incidentes o personajes de la escena política como "La devaluación", "Colosio", "Que regrese Salinas", "Ruta 100", "San Juanico". También hay letras que remiten al valor y a la esencia del rock, a su ponderación no solo como ritmo o música, sino también como un estado o incluso metafóricamente como "deporte", por ejemplo “Adicto

1 A la selección de futbol mexicana se le conoce también como "El Tri" como abreviatura de tricolor por los tres colores de la bandera mexicana (verde, blanco y rojo). 
al rock \& roll", "El rock nunca muere", "Esclavo del Rock and roll", "Inyecciones de rock and roll", "Que viva el rock and roll".

De manera particular nos parece interesante los primeros años de Lora ya con El Tri, porque se mueve aún dentro de sociolectos barriobajeros, letras existenciales y la descripción del submundo urbano dentro de una época caracterizada por la estigmatización contra el rock y el rechazo de los medios audiovisuales. De manera particular esa transición se da en los ochenta cuando Lora deja los circuitos marginales y comienza una proyección nacional, incluso con presentaciones fuera de México. Es la llamada "década perdida" de los ochenta cuando Lora comienza a tener una presencia nacional en un entorno generalizado de crisis; por otra parte, Lora asume una especie de defensa del rocanrol iniciando su propia lucha para limpiar la imagen de este género que en las dos décadas anteriores fuera tan reprimido y relegado por las autoridades, la sociedad, las disqueras y de alguna manera el cine.

En sus inicios llamado Three souls fue producido por el sello discográfico Comrock, que por una corta temporada se dedicó a grabar, producir y distribuir discos de grupos nacionales, pero en 1988 la compañía transnacional Warner Music Group (WMG) compró la disquera y las bandas pasaron a ser parte de su catálogo luego de que el sello se disolvió. Para el 1988, la WMG no le brindó ninguna promoción al disco, sin embargo, lograron un Disco de Platino con 50 mil copias, ya en 2005 la banda rompió relaciones con la WMG, Alex Lora se hace independiente y comienza su propia Lora Records bajo Fonovisa. En la difusión de la obra de Lora cabe señalar la gerencia de Celia Lora, pareja del cantautor, aparte de mánager, ha diseñado algunas portadas de los discos del grupo y producido sus eventos; ella ha influido en gran manera a que la construcción de realidad que se presenta como verdadera a través de los productos comunicativos, no satanice al rock. Se estima que El Tri ha vendido más de 30 millones de discos en su carrera, y fueron cinco nominaciones para el Premio Grammy (TERRA, 2009; WIKIPEDIA, s.f.).

\section{Breve nota a propósito de la discografía}

Proponemos caracterizar a Lora como comunicador y cronista urbano de México no solo por sus referencias a algunos aspectos de la realidad mexicana, sino por la descripción de unos tipos urbanos, el señalamiento del tipo de habla y la entera vindicación del rock. Aparte de mostrar su realidad, Lora ha sabido denunciar la corrupción, las injusticias, la opresión de las clases marginadas, y ha demostrado en sus composiciones preocupación por algunos sectores sociales como los niños y adolescentes desamparados (PEDELTY, 2004) que frecuentemente aparecen en sus letras. 
En otro nivel observamos que Lora presenta matices distintos que en su conjunto pueden verse como paradójicos: repertorio de canciones en las que puede abundar alusiones al sexo, la droga, el desmán o el desorden por una parte, y en contrasentido otras con marcadas referencias convencionales a instituciones dominantes como la iglesia o expresiones de religiosidad popular mexicana como la Virgen de Guadaluape. De manera adicional, vemos también diferencias en el abordaje moral: visos liberales que aceptan la droga en algunas, y otras canciones (o "rolas" llamadas por Lora) de guiño homofóbico como en "Encuentro cercanos del tercer sexo" o misógino como en "Viejas del Distrito Federal" 2 .

En muchas de sus letras Lora hace menciones contra la autoridad y el abuso, la opresión y la pobreza, además al provenir de los espacios contraculturales, hoyos fonkies ${ }^{3}$ y mundo suburbano que sintonizan con los lugares enunciativos de la inconformidad social; empero ello no hace de Lora un "cantor de protesta", ya que El Tri nunca se asocia a procesos reivindicativos ni luchas populares específicas. Si algo caracteriza las letras de Lora es esa denuncia llana de quien dice las cosas tal cual son dentro de los códigos de un lenguaje coloquial, plagado de altisonancias, y en ocasiones juegos de calambur local como el "albur", especie de poética popular como los escuchamos en "El Enmascarado de Latex".

El primer disco ya como El Tri fue Simplemente (1984) en la entonces alternativa firma Comrock. Fue el primer disco de rock en obtener un Disco de Oro de la industria mexicana por haber vendido más de 100 mil copias. De este disco quizá la canción más famosa sea "Triste canción" que es de sus sencillos más emblemáticos: la canción describe una relación de amor, metafóricamente asociada a cuestiones míticas ${ }^{5}$ es una pieza de letra original que da un sentido particular a la idea del amor erótico. Lora inició desde entonces un movimiento meteórico. En 1985 lanzó el álbum Hecho en México, al año siguiente Niño sin amor. En 1988 publicó Otra tocada más, donde en algunas letras recupera situaciones incidentes y ambientes de la época, como también lo va a realizar,

2 Esta es una canción que data de la época de Three soul in my mind, y se puede escucharla en: https://www. youtube.com/watch? $\mathrm{v}=\mathrm{LzGCjkE6jK0}$

3 Son esos espacios donde el rock se interpretaba en los sesenta y setenta. Estos lugares revestían una importancia central, porque fue ahí donde el rock puso subsistir, y donde grupos, cantantes, organizadores y asistentes podían correr algún riesgo sobre todo de persecución policial porque la actividad estaba prohibida. Estos "hoyos" podían ser lugares abandonados, bodegones, bares clandestinos o hasta espacios deportivos improvisados para la ocasión. La historia del rock mexicana está cargada de anécdotas, entre ellas se encuentra en Castañeda y Del Olmo (2012).

4 Letra accesible en http://www.musica.com/letras.asp?letra=2065357

5 "Ella existió, / solo en un sueño / el es un poema que el poeta nunca escribió / en la eternidad los dos / unieron sus almas / para darle vida / a esta triste canción de amor". 
en 1996, en Hoyos en la bolsa donde recupera los temas sociales acotados a la realidad nacional. En 1988 grabó su primer álbum en vivo, no en concierto cualquier, pero en una de las cárceles de la Ciudad de México.

En los noventa iniciaban con el disco Una leyenda viva llamada El Tri (1990), también viajaron por primer vez a los Estados Unidos (EE.UU.). Una de las canciones del disco "Millones de niños" recupera una temática en varios de sus sencillos con el tema de la pobreza en este segmento de edad. Debido al viaje a los EE.UU. incorporan el tema de los indocumentados en uno de sus sencillos y aparecen otros números que pudieran parecer anodinos tomando en cuenta la historia de Lora, pero que reflejan justo uno de esos rasgos más que heterodoxos, diversos en la letrística: en uno de los discos dedica una canción al famosísimo compositor de canciones infantiles Gabilondo Soler "Cri Cri”, quien marcó a generaciones de infantes y familias a través de distintas canciones en las que sabía “mexicanizar" el mundo de los sueños, los deseos y las historias.

De las peculiaridades en la discografía de Lora, encontramos la grabación de los discos sinfónicos, en el que Lora y su grupo cantan acompañados de una gran orquesta. En 1998 grabaron el primero de tres sinfónicos en vivo en el Auditorio Nacional ${ }^{6}$. Este disco es una conmemoración particular por los treinta años de carrera de Lora. Tres años después, ahora con la Sinfónica Metropolitana grabaron el segundo donde guarda las mismas características, y su música puede adquirir una nueva sonoridad donde lo pausado y armonioso de la gran orquesta contrasta con la voz abierta y delirante de Lora, así como el rhythm and blues.

\section{Recursos comunicativos y tensiones entre lo marginal y lo hegemónico}

El fenómeno musical no es únicamente sonoro o emotivo, sino también comunicativo y abarca distintos niveles de la expresión musical como práctica social. Por comunicación musical queremos aludir a varios procesos interrelacionados: desde los industriales y aquellos marcados por la organización de eventos hasta las cuestiones físico-sensoriales y las emotivas que hacen de la música un hecho, situación o momento que marca la vida de las personas y los grupos sociales. Ya la Escuela de Palo Alto (WATZLAWICK; BEAVIN; JACKSON, 1981) nos enseñó como la comunicación es algo más que la suma

6 Es considerado como uno de los principales teatros con capacidad para 10 mil habitantes. Igualmente es el teatro con más venta de boletos a nivel mundial. Para más informaciones consulte: http://allaccessworld.com. $\mathrm{mx} /$ index.php/eventos/item/404-el-auditorio-nacional-es-el-teatro-que-vendio-mas-boletos-en-el-mundo 
de los códigos verbales y no verbales, y constituye en realidad un conjunto muy heterogéneos de mensajes y códigos.

Así la comunicación musical es el conjunto de procesos asociados con la expresión musical y sus códigos (lingüístico, verbal, paralingüístico, gestual, escénico, etc.), las referencias y modos de alocución con las audiencias y los destinatarios, las huellas de reconocimiento y los sistemas de intercambio que puede haber entre lo que desde los estudios del discurso llaman instancia enunciativa y enunciataria; y finalmente esta comunicación implica una dimensión propiamente socio-cultural, interacción entre el grupo y sus audiencias como un armazón simbólico traducible en signos, símbolos y rituales que se pueden verificar en el escenario durante los conciertos, pero también en innumerables entrevistas en televisión, presentaciones de disco en distintos escenarios, afiches y demás materiales gráficos, impresos donde la construcción social del cantante o del grupo se construye, se actualiza o se modifica, ya que para el caso de Lora, la experiencia varía del hoyo fonky en los setenta a las versiones con orquesta sinfónica en el Auditorio Nacional.

Para describir algunos aspectos y funcionamientos de su éxito comunicativo, proponemos cinco puntos. Si bien el éxito se traduce comercialmente en ventas, cantidad de discos y sobre todo visibilidad, nuestra definición recupera un trasfondo de pragmático y comunicativo: la habilidad de ser fácilmente reconocido, la implicación afectiva que logra con audiencias que no son solo jóvenes de antaño.

El primero de estos recursos radica en el significante básico, la voz inconfundible, abierta, como si gritara, marcadamente rasposa (como si se estuviera desgarrando la garganta) y rockera. El primer mérito es el físico, la voz de Lora que con el paso de los años no pierde fuerza y sonoridad. Esa voz que con el paso de los años sigue identificable y con ella no solo canta, sino genera gritos y pronuncia interminablemente sus característicos estribillos como "que viva el rock and roll", "queremos rock", "que se oiga la banda..." y muchos llamados a esos grupos que se reconocen y asumen al conjuro de estas apelaciones.

Lora parece un signo de esa voz estridente al borde de la disolución, con la magia de no cansarse, como si con los años no menguara la fuerza de la misma. Su voz no parece ceder con los años y ahí encuentra la energía para una y otra vez repetir las apelaciones, los dichos, las imágenes, las frases y los estribillos como "el rock es un deporte, practícalo", "díganle a mi jefecita que está Alex Lora", "que se oiga la banda...", “...y los que le faltan...”. Ahí aparece en medio de cacofonías la convocatoria a esa multitud que se deja ser insultada, y que luego Lora solicita del público el mismo acto de habla para responder en un diálogo humorístico "gracias, público conocedor". Junto con los gritos vienen los bailes, los ademanes y las señas con las manos en ese conjuro 
del vínculo con la "banda", como llama a su público, comunidad imaginaria agrupada en torno a su voz y sus letras.

Tal vez uno de los recursos de la efectividad comunicativa de Lora se explique desde lo que llamamos "códigos de la mexicanidad" y que va más allá de sus letras y agrupa signos que aluden distintos contextos de la experiencia política, cultural y religiosa mexicana: banderas, símbolos religiosos, fechas y personajes, pero también atuendos, grabados o dibujos que se pueden encontrar en la guitarra, en las portadas, en las diversas camisas que por décadas se han vendido tanto en sus conciertos como en circuitos contraculturales. En este repertorio significa el valor de estos componentes semánticos en la estética y la comunicación musical.

Lora es rock, pero - y no es menor el gentilicio y el adjetivo- es rock mexicano, porque en su decodificación es necesario conocer dichos códigos, que forman parte no solo de sus letras, sino de sus códigos de relación con las distintas audiencias. Más allá que eso facilite el posicionamiento de Lora en sus conciertos en Ecuador o Perú, en Argentina o en el sur de los Estados Unidos, lo "mexicano" deviene en dispositivo ante sus audiencias, incluso en México, donde asistentes pueden ir portando una bandera mexicana, lo cual no parecería necesario en un concierto de rock en México, pero que funciona como un símbolo que refuerza la estrategia de agrupación, con lo que no solamente es rock, sino la constitución de un tipo de colectivo y "banda" que se semantiza en la interacción musical. La "mexicanidad" se asocia a un horizonte de interpretación que atraviesa distintos niveles comunicativos en la puesta en escena de Lora y que va de las constantes menciones (reales o irónicas) a la figura de su madre ${ }^{7}$ a la referida alusión a distintos símbolos de la religiosidad popular. Lo mexicano está ahí en un alarde (real o ficticio) de "superioridad" en la Ciudad de México, en los propios mexicanos o a nivel cultural en la canción "Canta Grillo", dedicada al mencionado Gabilondo Soler "Cri Cri”, que Lora destaca la mexicanidad de este compositor como un principio de reconocimiento y valor en sí mismo estimable ${ }^{8}$.

A lo mexicano se suma otro nivel discursivo, la idea de lo "esencial" y "original" como un componente de lo que se hace. Por ejemplo Lora decidió lanzar una bebida típica mexicana que no será la tequila, que es lo que pudiera esperarse, sino otra bebida vernácula que viene ganando mucha aceptación en los últimos años, el mezcal. Al respecto Lora explica la razón al periodista Pujals (2006):

7 Frecuentemente en broma o en serio Lora rompe su discurso para decir "mamá, enciende la televisión porque está saliendo Alex Lora, El Tri”. Llama también la atención este alocutario que no parece guardar vínculo con sus letras o con sus temas, y que, sin embargo, es incluyente. 
Porque es mucho más nuestro todavía. Y además es mucho más puro y natural. Es una bebida $100 \%$ artesanal, $100 \%$ natural que no contiene aditivos, preservativos ni químicos y que se extrae directamente del corazón del maguey. Además contiene mezcalina, como el peyote, entonces es un energético natural. Mientras que el tequila ya contiene mucha química, y ha sido muy comercializado. El mezcal es una bebida que solamente los dioses, los privilegiados pueden tomar...el tequila cualquier "güey" lo toma.

Cercano a estos recursos, identificamos en la comunicación de Lora una particular caracterización del rocanrol como una especie de totalidad, una atmósfera que explica y justifica lo que hace. El rock así aparece como deporte, espíritu, motivación, estímulo. Lora reivindica un cierto purismo del rock como estilo, actividad y casi sustancia. El rock aparece como un referente muy amplio que se adapta a distintas situaciones y cuyo destinatario puede ser cualquier persona, no es casual que en los conciertos de El Tri se vean no solo grupos de jóvenes, sino familias o parejas. Todos son parte de la "banda", que a nivel denotativo refiere el grupo musical, pero también se asocia al conjunto de pares como aparecen en varias de sus letras como "Cotorreando con la banda", en la que el rock es elemento integrador que facilita la libre expresión y la sensación de no tener problemas.

A pesar del destinatario abierto de Lora que ese alocutario es un "otro" imaginariamente juvenil que adquiere estatuto de membresía en torno al rock, al "verdadero", al marginal, es ese niño y joven "sin amor". Lora es con frecuencia irreverente con sus destinatarios, y ese alocutario, si bien se construye como el muchacho, parece dotar de un carácter juvenil al imaginario de sus audiencias que con el paso de los años migra del joven y rockero en Avándaro de 1971, al adolescente marginal de 1986, a las grandes audiencias en las que puede haber familias o generaciones que comparten a este ejemplo particular del rock funcional mexicano. Lora ha mostrado ser exitoso en la comunicación verbal con el flujo de interpelaciones, interjecciones, cacofonías, apelativos particulares, sociolectos; señas y movimientos fuera de cuyo contexto adquieren un carácter altamente ofensivo, pero que en la puesta de escena de este cantautor forman parte de una especie de relajo regulado, catarsis de una comunicación rápida y efectiva con esa "banda" de la que participa el público.

Sin embargo, como ya advertimos esta comunicación musical no está carente de tensiones fuertes y paradojas. Parecería que el rock urbano partía de una condición subterránea, desde la cual sus letras y el universo semántico que vehiculaba adquirían un cierto estatus y reconocimiento. Lora cantaba hace poco en espacios que le acercaban a sus orígenes, callejones o plazuelas donde el público juvenil ataviado de negro y con consumo 
de enervantes bailaba frenético sus canciones; pero igualmente en el Auditorio Nacional, icono del gran espectáculo y la consagración de cualquier artista. Hace mucho tiempo que Lora no representa más el submundo urbano ni la marginalidad en la expresión; permanece como una figura, que al margen de su realización musical o su actualización, a un nivel se convierte en signo ya no solo para referir al rocanrol, sino a otros códigos asociados a su performance como músico: espectáculo, diversión, entretenimiento.

Así se presenta este rasgo de contradicción con las instituciones. Ya mencionamos que el que Lora mencione quejas e imprecaciones contra la autoridad no lo hace un "cantor de protesta". Como vamos a mencionar adelante, parece tener una relación contradictoria con las instituciones dominantes: iglesia, grandes medios, auditorios particulares (como el Auditorio Nacional) que distan de escenarios contraculturales por donde alguna vez circuló. Este movimiento, no es algo que vaya junto al ascenso o reconocimiento del cantante, sino que igualmente una particular erosión de su contenido contracultural e irreverente. El problema de Lora es que puede simular que canta contra las instituciones o los valores dominantes, pero vive - al menos ya desde unos años - vinculado o asociado a ellas, al menos por lo que podemos deducir de sus conciertos en el Auditorio Nacional o su inesperada presencia en las "mañanitas" a la Virgen de Guadalupe, o una anodina canción titulada "Juan Pablo II" en el disco Más allá del bien y del mal (2005). En otoño de 1988 durante la gira Fin de Siglo, Lora apareció en el escenario con una camisa que llevaba la imagen de la Virgen de Guadalupe. En 2002 aparecía la canción "Solamente Dios", lo que podría contrastar de hecho con los valores y la estética del rock marginal y la expresión contracultural que por momentos tuvo este género.

\section{Sujeto y temática en la estética urbana}

\section{El "Niño sin amor" o el rostro afectivo de la marginación}

Durante una etapa de su producción, Lora se movió en espacios contraculturales en el que los sujetos principales correspondían a personajes de submundo urbano: jóvenes, adolescentes, nonatos o bien personajes que se caracterizan por algún grado de frustración frente a la realidad. En muchas de sus letras encontramos la caracterización de niños o adolescentes carentes de estructura familiar, abandonados y con un elemento de carencia emocional o afectiva, como es expresado en una de sus canciones más emblemáticas "El niño sin amor". En otras letras es posible reconocer estos retratos muy amplios y generales, rasgos en realidad de lo que no es una psicología de la marginalidad, sino una indicación de componentes generales. También vemos las 
reiteraciones a esos sujetos discursivos, que nunca hablan, sino que son descritos por la voz enunciadora.

En suma, podemos encontrar referencia a la construcción de sujetos que atraviesan por distintos niveles, de manera particular a los niños tanto en su condición de marginados socialmente, como de las propias dificultades. Esto puede identificarse con claridad en "Pamela", "El niño sin amor", "Millones de niños" y "Pobres niños", todas con adaptaciones de rhythm \& blues, en tiempo lento (balada) y en el que retoma la clásica composición de blues y sus variaciones (Introducción, Verso, Coro, Verso, Puente musical de algún instrumento líder, verso, Coro y Salida), por otra parte, las melodías son con instrumentación típica de guitarra rítmica, guitarra líder, bajo, batería, así como se puede añadir saxofón, harmónica y piano.

Estas canciones se produjeron en 1987 a 1996, periodo en que como hemos mencionado el país estaba dentro de una fuerte crisis económica y en 1994 se sumó la crisis política. El entorno era de desánimo general. En paralelo Lora realizaba una especie de defensa del rocanrol a nivel subterráneo, iniciando su propia lucha para limpiar la imagen de este género tan estigmatizado, reprimido y relegado por las autoridades y por la sociedad. En este periodo, El Tri salía de los hoyos funkies que eran casas en estado ruinoso, fábricas abandonadas, y cines o teatros medio derruidos, para llegar a mejores escenarios invirtiendo en la producción y la infraestructura que no existía en el medio del rock, y teniendo que disfrazar de esa manera el festejar año con año el aniversario de Avándaro por la represión que existía llamándolo "El día del Rocanrolero Mexicano".

A su manera Lora facilita la visibilización de una situación difícil de niños y adolescentes. Por ejemplo de acuerdo a una nota del diario El Universal del 2014, el $53 \%$ de los niños y jóvenes de 0 a 17 años de edad son pobres, 3 de cada 10 pasan "hambre", además de que 6 de cada 10 niños sufren maltrato infantil (FORBES, 2014), por lo que observando solamente los símbolos y el código del mensaje de las canciones, podemos aludir que son realistas, tratan sobre la vida cotidiana y de hechos sociales.

En todas estas letras, El Tri toma la forma de narración. En su caracterización Lora subraya la inocencia y vulnerabilidad de los niños que contrasta con lo duro y hostil del mundo suburbano. En los relatos se describe ese mundo en el que se encuentran niños y jóvenes, encontrando oposiciones entre la inocencia y la maldad, la pobreza extrema y la opulencia, etc., además describen una sociedad que maltrata física y psicológicamente al menor de edad. Así Lora muestra una sociedad insensible, sin razones y valoración social; y contrapone lo que se quiere mostrar versus una realidad caracterizada por pobreza, desigualdad, miseria, daño, indiferencia ante algunos seres humanos. 
El relato cantado por la voz dominante es directo dentro de escenas cruentas y dolorosas. En "Pamela" por ejemplo se cuenta cómo una madre le quita la vida a su hija, porque no tienen para mantenerla. En los relatos Lora usa la voz indirecta en el que incorpora el supuesto punto de vista del niño que le parece un mundo extraño. Al margen de la realización literaria o lo cuidado de la estrategia retórica, el componente llano de un hecho que se presenta tal cual, en código que sobre todo quiere renunciar a cualquier tratamiento que maquille lo que para el letrista es lo más importante: presentar la realidad tal cual a partir de lo injusto que resulta para los niños el hecho de que haya riqueza y superficialidad cuando hay niños que mueren de hambre.

\section{La ciudad como escenario o las tensiones de la convencionalidad}

Dentro de su carácter como narrador, Lora ha dedicado varios números a aspectos de la Ciudad de México. Con realización muy desigual, y con asuntos o temas no frecuentes dentro de la letrística del rock, Lora repasa estaciones de autobús, del metro o calles de la ciudad donde básicamente refleja escenas y situaciones sin que ello suponga una problematización real de esos asuntos. En muchos de estos escenarios como "Metro Balderas" (no en el original de él, pero también dentro de su repertorio) o "A.D.O." los personajes intentan sobrellevar la decepción en estos espacios de paso que recuerdan o supone el lugar de quiebre; así estos espacios adquieren un particular valor simbólico de inicio o cierre de una relación. Otra canción que alude al medio de transporte urbano es "El fantasma del metro", pero la letra no está caracterizada desde la dinámica afectiva del personaje discursivo, sino que aparece casi como una postal imaginaria de un supuesto fantasma que viaja con todos los usuarios.

Dentro del lenguaje directo y sin ambages, Lora denuncia y se ríe al mismo tiempo, recupera giros y situaciones a las que ciertamente presenta de manera clara, y al mismo tiempo con ello puede quitar densidad a los trasfondos. Por ejemplo en "Chilango incomprendido" recupera el tema de la migración a la Ciudad de México, que por la década de los ochenta comenzaba una campaña para inhibir la migración a la capital del país y aquí realiza una operación que parece contradictoria, porque secunda en parte el discurso oficial en tanto impedirla, pero sin ir más allá de las causas que la originaron, así consciente o no Lora reacciona ante una situación, pero lo hace desde marcos institucionales.

La Ciudad de México como gran concentración ha atraído expresiones de filiación, afecto e intimidad, como de odio, extremo malestar y decepción. En el caso de Lora, en "Chilangolandia" refleja una visión a veces ingenua, pero afectuosa, en la que a su manera hacía una "declaración de amor" a la ciudad en la cual quiere destacar su 
monumentalidad y diversidad, así como un principio de centralidad en lo que, por otra parte, es una tendencia cultural de la expresión popular, y la costumbre de mirarse al ombligo.

Con frecuencia los temas sexuales no adquieren una visión actualizada de tolerancia e inclusión, tal es el caso de "Encuentro cercanos del tercer sexo", en el que juega con el título de la película famosa, Encuentros cercanos del tercer tipo, del realizador Steven Spielberg, en la que narra -usando el viejo nombre de una avenida importante en la Ciudad de México (conocida hace tiempo como San Juan de Letrán hoy llamada "Eje Central") - el caso de un travesti (hombre vestido de mujer) que se le acerca al narrador; la voz comenta su decepción y hace fuertes juicios contra este personaje; la ciudad aparece como ese lugar parcialmente abierto de mujeres atractivas como lo dice en la canción, pero la voz narrativa refleja una actitud muy prejuiciosa hacia el travesti. De esta manera, vemos como las letras de Lora se mueven en planos distintos, como la denuncia de los problemas que aquejan a la niñez, versus asuntos de derechos sexuales. A pesar de ser el rock un espacio para la libre expresión sexual, éste conserva los visos de una perspectiva principalmente heterosexual, canónica y preestablecida. En ese sentido Lora no actúa como una voz contracultural o contestaría, o lo hace a propósito de algunos temas como ejemplo la denuncia de la arbitrariedad policial en "Abuso de autoridad", letra que se ubica dentro del espacio urbano, pero no lo hace desde las huellas emblemáticas de la Ciudad de México; o bien en una canción de la primera época "Blues del Eje Vial" donde la voz narrativa denuncia obras de diseño urbano en perjuicio de las necesidades reales de la gente.

De estas miradas a la subjetividad de sus habitantes quizá uno de los aspectos más interesantes fue la recuperación de la creatividad en la expresión a partir del calambur, juegos de la palabras o como se le conoce en México el "albur", en el que deja ver la creatividad del habla popular en esa especie de "poética pragmática" si tal término cabe, como en el "El Enmascarado de Latex" en el que alude al doble juego del lenguaje de connotación sexual. De esta manera, Lora comparte uno de los mejores recursos escapistas del habla, la subjetividad y creatividad de los hablantes como una forma de reinventar el mundo cercano a través de estos recursos que huyen de cualquier interpretación funcional.

Sin restar méritos a la figura de Lora, ésta tiene que ser reencuadrada en un contexto que permita ponderar esos dobleces y figuras de algo que aparece como más complejo de lo aparentemente simple y eficaz. Lora es un rockero en la construcción de lo que él mismo ha hecho de ese género, en su comprensión y la singular ejecución que lo ha logrado. El principal logro es el de su presencia, el de su transversalidad en generaciones, 
asuntos y situaciones en las que creemos que la principal consecuencia es que desfigura el sentido contracultural hacia otros niveles más funcionales y de circulación. En su estética, si bien es simple, clara y sin mucha elaboración, salvo algunas piezas como la señalada arriba, eso no resta mérito a canciones que ilustran una sensibilidad, que aun cuando hoy migre en estos espacios sociales convencionales y en los medios, reflejan la capacidad de Lora en mostrar las posibilidades comunicativas de la canción rockera, así como en tejer algo de su capacidad de agrupación en el mundo suburbano; y al mismo tiempo es un sujeto social con capacidad de adaptarse, de contradecirse y volver a cantar, con contundencia y estilo, “Triste Canción”, o "Pamela". Así Lora es al mismo tiempo aquél que critica a la televisión privada (como en las canciones "La caja idiota" o "Canal de las Estrellas") pero que luego termina en tensa sintonía a través de un rock que a nivel no es lo que reivindicaba en su producción en los setenta o parte de los ochenta, y que si bien Lora siempre será el compositor de piezas emblemáticas del rock urbano, muestras de las paradojas de la exuberancia expositiva y los sinsabores de la funcionalidad de su imagen pública en los grandes medios masivos.

\section{Referencias}

CASTAÑEDA, L. F.; DEL OLMO, A. De Avándaro al Vive Latino. Excélsior, 2 de enero 2012. Disponible en: <http://www.excelsior.com.mx/2012/01/02/funcion/798501>. Visitado el: 12 feb. 2016.

EL ROCK no tiene la culpa. Director: Miguel Ángel Hernández Sierra. Producción: Miguel Ángel Hernández Sierra. México, 2011. 45min.

NOCHES CON PLATANITO. Alex Lora canta en exclusiva. 2013. Disponible en: <https://www.youtube. com/watch?v=eK_4V1oXD94>. Visitado el: 20 nov. 2015.

PEDELTY, M. Musical Ritual in Mexico city from the Aztec to NAFTA. Austin: University of Texas, 2004.

PUJALS, A. C. EL TRI: Con 38 años a puro rock and roll, festeja con nuevo disco en vivo y mezcal propio. Auténtica comida mexicana de Silvia Ibarra. 2006. Disponible en: $<$ http://www.elportaldemexico. com/arte/musica/eltri.htm>. Visitado el: 3 feb. 2016.

RETRATO de Alejandro Lora. Director: Francisco Javier Padilla. México: Pandilla Films. 2008. 20min.

TERRA. EL TRI celebra 41 años en el Auditorio y lanza nuevo álbum. 2009. Disponible en: <http://musica. terra.com.mx/el-tri-celebra-41-anos-en-el-auditorio-y-lanza-nuevo-album,5699fdddd4e2f310VgnCLD200000bbcceb0aRCRD.html>. Visitado el: 25 nov. 2015.

WATZLAWICK, P.; BEAVIN, J.; JACKSON, D. Teoría de la comunicación humana. Barcelona: Herder, 1981.

WIKIPEDIA. EL TRI (banda). [s.f.]. Disponible en: <https://es.wikipedia.org/wiki/El_Tri_(banda)>. Visitado el: 20 enero 2016. 